\title{
Gamification in Management and Other Non-Game Contexts-Understanding Game Elements, Motivation, Reward Systems, and User Types
}

\author{
Oliver Mauroner \\ School of Business, Mainz University of Applied Sciences, Mainz, Germany \\ Email: oliver.mauroner@hs-mainz.de
}

How to cite this paper: Mauroner, O. (2019) Gamification in Management and Other Non-Game Contexts-Understanding Game Elements, Motivation, Reward Systems, and User Types. Open Journal of Business and Management, 7, 1815-1830. https://doi.org/10.4236/ojbm.2019.74125

Received: September 6, 2019

Accepted: September 27, 2019

Published: September 30, 2019

Copyright $\odot 2019$ by author(s) and Scientific Research Publishing Inc. This work is licensed under the Creative Commons Attribution International License (CC BY 4.0).

http://creativecommons.org/licenses/by/4.0/

\begin{abstract}
Gamification is the use of gaming methods and ways of thinking in non-game economic and social contexts in order to solve some kind of problems. Possible applications of gamification are currently the subject of broad-based discussion in marketing and management in particular. Expectations are very high, primarily in those areas in which motivation processes have a large part to play. In order to fully exploit the potential of gamification, a profound understanding of modes of operation in gamified systems is needed. This then enables a productive transfer of game elements to non-game contexts, taking into account user typologies and including the requirements of very different application scenarios. This article takes up the findings of different theoretical and empirical studies on gamification from various perspectives. It combines the findings into an integral perspective and provides a catalogue of core elements of gamified systems. Approaches to reward mechanisms in gamified systems are worked out on the basis of fundamental motivation theories. It is argued that a simple adoption of award systems cannot be productive; the different kinds of needs of users with regard to social interaction, attractive challenges and individual development opportunities must, rather, be incorporated into the design of gamified systems. The article offers practitioners and researchers new impetuses for further engagement with gamified systems.
\end{abstract}

\section{Keywords}

Gamification, Motivation, Non-Game Contexts, Gamified Systems

\section{Introduction}

Playing and playful behaviour have a particular significance for the human indi- 
vidual from birth onwards. Children "play" automatically, e.g. when they transform a walk into a hopping game, trying not to step on the gaps in the paving stones. Adults "play", e.g. when they mow the lawn, making particular patterns of their own with the lawnmower in order to break the monotony of what is actually a mindless activity. Children and adults construe their very own, individual motivation and reward systems in a playful way.

Back in his day, Friedrich Schiller the German poet and philosopher was already concerned with the phenomenon of playing and its effects on the human psyche. In his letters on the aesthetic education of man he wrote: "[...] Man plays only when he is in the full sense of the word a man, and he is only wholly Man when he is playing" [1]. Playing represents a primeval human activity, its motivation proceeding from the innermost core of each person. In this it is possible to identify a few fundamental prerequisites for the genesis of play, which Deterding (2012) describes as [2]:

- clear rules, a compelling story and challenges arising from this;

- clear aims and direct, immediate feedback on actions;

- free, protected spaces in which it is possible to interact with others.

Gamification has raised significant interest both in academia and industry in the last few years [3]-[8]. However, the principle of introducing gaming elements in other contexts is not new; it has been used for decades or even centuries. It is used by the armed forces and boy scouts, and martial arts students, too, are familiar with the elements of gamification: badges signal a certain status within a particular community. A higher status can be achieved through performance, through particular behaviour, or by completing tasks.

\section{Gamification and Gamified Systems}

According to Kapp (2012), gamification means “... using game-based mechanics, aesthetics and game thinking to engage people, motivate action, promote learning and solve problems" [9]. A game, accordingly, can be defined as a recreational activity conducted within a framework of agreed rules [10]. Piaget (1951) classifies games in three clusters: exercise games, symbolic games and games with rules [11]. The first category is exercise games where both the senses and movement are involved. Symbolic games rely on the player's imagination and include role-play. Finally, the third group is a form of play that involves rules, like racing or football [12]. Gamification therefore denotes the use of game elements in non-game contexts with the aim of solving problems. In this there are manifold fields of application: websites, work processes or services. Wood and Reiners (2012), for example, have studied gamification in the field of logistics and supply chain education [13]. Paharia (2013) focuses on the aspect of motivation, arguing [14] that "gamification is motivating people through data. [...] gamification takes the motivational techniques that video game designers have used for years to motivate players and use them in nongame contexts." Also Müller, Rise and Seliger (2015) come to the conclusion that gamification leads to higher student participation and encourages the development of the student's 
social, personal and technical competences [15]. In arguing this, the authors refer especially to the use of gamification in the digital context. Nowadays, both goods and services and the successful completion of tasks effectively take place, above all, in the digital space, and the available rewards are frequently of an immaterial nature. At the same time, many authors elaborate the connection between gamification and big data, i.e. the production, storage and use of enormous amounts of data [16]. The ubiquity of information and communication technologies such as internet, smartphones, TV and household appliances are essentially developments that advance the distribution of gamification in the digital and also in the analogue world. In fact, with the rapid development of mobile devices such as smartphones, gaming becomes mobile and allows a dynamic interaction [17]. For example, individual tooth brushing behaviour can be optimised with the aid of gamification by the electric toothbrush storing data, transmitting it to the smartphone and aligning the data with information that is already available. Manufacturers of sports goods offer options to compare the own training behaviour with the goals we have set ourselves and with the achievements of other members of sport communities. The result of these developments is that each person produces enormous amounts of data that can be accessed and used by businesses and other organisations in order to individually adapt their service offering. It is precisely the connection between big data and gamification that makes it possible to develop game elements and adapt them individually to the user or customer. Gamification is therefore linked to high expectations as regards the development of new application scenarios [18].

In marketing and management contexts gamification is predominantly understood as a motivation concept that is integrated into available platforms, structures, products, services or processes. With the aid of gaming elements, game design and data, an-as far as possible intrinsic-motivation can be evoked among different target groups. This operational principle of generating intrinsic motivation is ultimately employed in very different fields of application, e.g. in the field of training and continuing education, in the health sector, in the organisation and improvement of work processes, or in increasing customer retention. Zichermann and Cunningham (2011) even assert that gaming elements can be used in any problem in which motivation and human behaviour have a part to play [19]. Xu, Tian, Buhalis, Weber, and Zhang (2015) for example notice the opportunities of gaming in the travel and tourism sector by providing unique experiences before, during and after a journey [20]. The use of gamification is therefore not limited to scenarios in the fields of marketing, management and education. Nonetheless, the expectations of gamification are also given critical consideration, e.g. in the Gartner Hype Cycle [21]. Within this concept, technology trends are represented together with development perspectives and current stages of productivity on an annual basis. According to the current Gartner Hype Cycle, gamification is on its way towards an anticlimax, which is equivalent to saying that the so-called "plateau of productivity" can be reached only after substantial further development and professionalization, to remove the caus- 
es of currently unexploited potential. This could be achieved probably within the next five to ten years. Kirst (2013) sees these causes in both the poor design of the elements and an inadequate definition of concrete applications and targets for gamification [22]. It is too often the case that apparently superficial elements such as, for example, points, awards and progress bars seem to be used in an arbitrary way just to gain attention in the short term. Although these elements are part of the effective mechanisms of gaming motivation concepts, their use should, however, be adapted to the core challenges and targets of the systems, the characteristics and needs of the target groups, and the corresponding changes over a specific period of time. In order to fully deploy the potential in gamification, the concepts must more strongly focus on addressing the long-term intrinsic motivation of the customers and not lose themselves in the temporary quest for attention. In connection with this, Marczewski (2014) says [23]: "As time has gone by, Gamification has evolved and people are looking more at what I call Motivational Design.” In his recent paper Deterding (2019) argues that through gamification, management could become more open, indeterminate and potentially transformative [2].

\section{Motivational Concepts of Gamification}

Researchers tend to agree in saying that games are used for enjoyment and to satisfy the needs for competence and relatedness [20]. However, understanding the motivation of game players is an under-researched area [24] although studies of motives for playing digital games are mainly grounded in theoretical models, and they are mostly based on satisfaction of needs [25]. Main game players' motivations identified by researchers are summarized in Table 1 .

Table 1. Game players' motivations.

\begin{tabular}{|c|c|}
\hline Motivation & Literature \\
\hline $\begin{array}{l}\text { Challenge, achievement, } \\
\text { and competition }\end{array}$ & $\begin{array}{l}\text { Deci and Ryan (1985) [23]; Lucas and Sherry (2004) [27]; Ryan, Rigby, } \\
\text { and Przybylski (2006) [24]; Yee (2006) [28]; Li and Counts (2007) [29]; } \\
\text { Tychsen, Hitchens, and Brolund (2008) [30]; Frostling-Henningsson } \\
\text { (2009) [31]; Engl and Nacke (2012) [32] }\end{array}$ \\
\hline $\begin{array}{l}\text { Socialization, social } \\
\text { interaction, and sense of } \\
\text { belonging }\end{array}$ & $\begin{array}{l}\text { Ryan, Rigby, and Przybylski (2006) [24]; Yee (2006) [28]; Lin and Lin } \\
\text { (2011) [33]; Lin, Chen, and Kuo (2011) [34] }\end{array}$ \\
\hline Excitement and arousal & Lucas and Sherry (2004) [24] \\
\hline $\begin{array}{l}\text { Escapism, kill time, and } \\
\text { freedom in virtual world }\end{array}$ & $\begin{array}{l}\text { Yee (2006) [28]; Ryan, Rigby, and Przybylski (2006) [24]; Chou and Tsai } \\
\text { (2007) [35]; Tychsen, Hitchens, and Brolund (2008) [30]; Mintel (2009) } \\
\text { [36]; Frostling-Henningsson (2009) [31] }\end{array}$ \\
\hline $\begin{array}{l}\text { Immersion (discovery, } \\
\text { role playing, } \\
\text { customization) }\end{array}$ & $\begin{array}{l}\text { Paras and Bizzochi (2005) [37]; Yee (2006) [28]; Tychsen, Hitchens, and } \\
\text { Brolund (2008) [30]; Carrigy, Naliuka, Paterson, and Haahr (2010) [38]; } \\
\text { Engl and Nacke (2012) [32] }\end{array}$ \\
\hline $\begin{array}{l}\text { Flow, positive emotions, } \\
\text { perceived usefulness, and } \\
\text { fantasy }\end{array}$ & $\begin{array}{l}\text { Paras and Bizzochi (2005) [37]; Zhou (2012) [39]; Engl and Nacke (2012) } \\
\text { [32]; Huang, Backman, Backman, and Moore (2013) [40] }\end{array}$ \\
\hline
\end{tabular}


In order to gain a profound understanding of gamification the fundamental, underlying motivation concepts of human action must be considered, i.e. intrinsic and extrinsic motivation [26]. According to Ke, Tan, Sia, and Wei (2012), intrinsic motivation exists where an activity is carried out for its own sake [41]. Extrinsic motivation, on the other hand, exists where people devote themselves to an activity on the basis of its consequences, e.g. an expected reward or punishment. In many contexts intrinsic motivation is regarded as more effective than extrinsic motivation, e.g. in successful learning [42]. Paharia (2013) emphasises here, however, that extrinsic motivation does not necessarily have to be inferior to intrinsic motivation [14]. In fact, the boundaries between these two concepts are blurred, so it is not always easy to tell the difference. There may, then, be different motivations for going to the gym: the incentive might be to feel healthy, burn fat, or regain one's figure in order to be attractive in general or for a particular person [14]. The motives are derived from an inner incentive (health) as much as from outside (admiration). Gamification is likewise based on a mix of both motivation concepts, whereby external incentives are used to stimulate an intrinsic motivation.

There are different approaches to explaining why games in virtual or real spaces engender fun and motivation. On the one hand, rewards in the form of points, awards and virtual goods influence human behaviour positively [3]. On the other hand, when playing, feelings of happiness come about directly when people meet challenges they have voluntarily set themselves. Here, too, it is clearly a combination of intrinsic and extrinsic motivation. Generally, different theories can be drawn on to explain the bundle of motivations. The self-determination theory according to Ryan and Deci (2000) [43] and the flow theory according to Csikszentmihalyi $(1990,1997)$ [44] [45] are frequently cited in explaining the effectiveness of intrinsic motivation [9] [19]. The former (Kapp, 2012) [9] describes how the quality of behaviour and the accompanying sense of well-being are positively linked with the respective degree of autonomy of the underlying motivation. According to the flow theory, a particular feeling of happiness arises as the result of complete immersion (concentration) and complete absorption in an activity (absorption). In this, it is crucial that there is a balance of challenge and ability, so that there is neither too little nor too much challenge. Fogg's (2003) [46] behavioural model or the principle of operant conditioning by Peter and Nord (1982) [47] are drawn on in connection with extrinsic motivation. Both of these seek external triggers for modes of behaviour. Gamification, however, is focused on internal human incentives and hence intrinsic motives, with four core aspects being frequently discussed:

- Social integration denotes the human desire to be connected with other people and interact with them.

- Striving for autonomy denotes the desire to define one's own life oneself and act freely within the scope of one's own possibilities.

- The aspect of mastery expresses the ambition to continually improve oneself and recognise progress. 
- Finally, significance denotes the human desire to do something of greater significance - a significance that extends beyond the single individual.

\section{Key Elements and Reward Categories of Gamification}

\subsection{Key Elements of Gamified Systems}

The use of gaming concepts and methods cannot be equated with the complete integration of independent games into products, services or work processes. A clear distinction must therefore be made between games themselves and gamification. The latter describes the adaptation of principles and elements from games, and their use in a different context in order to evoke, through play, a motivation and a desired form of action. These key elements of gamification are extremely diverse, extending far beyond the aforementioned points allocation. The following Table 2 gives an overview of key elements of gamification which generate intrinsic motivating factors.

The individual elements are explained in more detail below [9] [14] [19]:

- Feedback: Users receive immediate feedback on each of their actions. In computer games this in the form of points, remaining time, or energy level. Players also glean from this information on whether their actions were "right" or "wrong". The use of feedback elements is based on the assumption that in gamified contexts it is necessary to communicate directly with users. Games provide feedback that makes outcomes comprehensible, such as badges in video games. Other examples include thanking users for the actions they have executed, conveying current news to them, keeping them informed on the current situation, or suggesting next possible steps.

Table 2. Overview of selected key elements of gamification.

\begin{tabular}{|c|c|}
\hline Element & Explanation \\
\hline Feedback & Direct response to actions executed \\
\hline Transparency & Openness and clarity regarding data used \\
\hline Objectives & Structured, step-by-step tasks \\
\hline Storytelling & Stories to escalate motivating strands of action \\
\hline Points & Points as visible feedback momentum \\
\hline Levels & Progress index and controlling of degrees of difficulty \\
\hline Badges & Signalling status within system and community \\
\hline Onboarding & Direct entry without further explanation \\
\hline Contest & Competition between users as motivating components \\
\hline Collaboration & Addressing social needs trough working together as a community \\
\hline Time & Time and time pressure as feedback elements and motivating factors \\
\hline Repetition & Opportunities for repetition to stimulate learning \\
\hline Personalisation & User adaptation via elements of personalisation \\
\hline The unexpected & Unexpected effects through breaking the monotony \\
\hline
\end{tabular}


- Transparency: A transparent and comprehensible use of data is essential for issuing feedback and, in general, for the use of gamification as a motivation concept. It is crucial that the data, e.g. information on targets met or comparisons with other users, are visible and clearly comprehensible.

- Objectives and Tasks: Successful games are frequently about fulfilling an exciting mission and completing fiddly tasks such as the manipulation of blocks in a Tetris game. Setting objectives has an important role in gamified contexts, too, for in this way user behaviour can be directly controlled. In this sense, objectives and tasks should, on the one hand, be oriented by the user's individual progress, and, on the other hand, conform to the system context. Detailed description of the objectives set, explanation of the basic conditions of implementation, representation of impacts and effects on the user, and finally, references to other users and their status have a significant part to play in success.

- Storytelling: Objectives and concrete instructions for action within a gamified system can be packaged in stories and are thereby easier to remember. At the same time, continuous strands of action have a motivating effect, particularly when they are connected with intermediate objectives and direct feedback.

- Points: Points are a fundamental element in gamified systems. This is the case whether they are visible to the outside or merely provide data on users and their activities internally. With the aid of points, system designers can motivate their users to do certain things, set priorities and carry out targeted actions. Points contain a feedback momentum and make it possible to track and follow up on user actions. In general, different kinds of points are differentiated. Experience points represent the experience or performance of users and, at the same time, from the system operator's point of view, serve to assess and guide the user. Similarly, there are so-called karma points which can be awarded by users to other users, e.g. for the quality of contributions. Redeemable points can be used by users or exchanged for other things. This can be effected within the system or against external rewards. These points represent a value for the users, and through the possibility of exchange they constitute a virtual economy. Skill points are awarded for particular activities and achievements, e.g. the quality of photos. They can, at the same time, correspond to experience points or redeemable points. Reputation points serve to build, and make visible, trust within the system and between several users. An example is rating points for online traders awarded by their customers for product quality, product description and delivery terms.

- Levels: Because point systems and corresponding successes in the accumulation of points often remain abstract for users, a transfer in levels or progress levels occurs frequently. In addition to the function of the progress index, levels have a motivating function because of their direct external impression. Levels are an expression of a certain status and are familiar in everyday life, 
e.g. in sport or the military. At the same time, they symbolise time and resources expended in a (game) system. Players' or users' actions can be directed with the aid of levels. The principle here, according to the flow concept, is that in order to trigger corresponding feelings of happiness it should be increasingly difficult to advance through the levels.

- Badges: In games as well as in gamified contexts in the virtual and real world, particular symbols, e.g. badges, titles and stickers indicate achievements or existing competences. If badges are connected to tasks that have been set previously, they visually communicate the achievement of the objectives. It is essential that these badges are visible to other actors and that they can be evaluated in terms of the statement they are making. For example, in the context of travelling a national flag may represent repeated visits to the respective country, and the title "globetrotter" may represent visits to a certain number of countries.

- Onboarding: The principle of onboarding is based on the assumption that the first interactions with a system are of utmost importance further down the line and for procuring repeat business. Users are introduced immediately and directly into the gamified context and enabled to gain their own experience. In contrast, detailed explanations and instructions are given only in due course, following the principle of "learning by doing". This creates step-by-step incentives for further actions.

- Contest: Games frequently contain various competitive components, particularly competition against oneself or against other players. In gamified systems this is expressed in the form of points comparisons and ranking lists. This involves the principle that new and inexperienced users can be motivated by individualised ranking lists and competition elements.

- Collaboration: Within games, and especially within gaming contests, opportunities can be created for users to connect with other users in order to achieve particular objectives as a community or as a smaller group. The element of collaboration addresses the social needs of the users and can, at the same time, trigger group dynamic effects. This includes, for example, striving to contribute to the success of the group and to not be the weakest group member. The aspect of user community within the system lends other elements (points, contests, badges) an additional motivating effect.

- Time: Time and time pressure in games and in gamified systems serve both as a feedback element and as a critical resource, and therefore as a motivating factor.

- Repetition: The possibility of repetition within gamified systems offers users the chance to try out tasks a number of times. This allows them to take risks, make mistakes and test out options. This also stimulates curiosity and the willingness to experiment, and ultimately leads to improvements with regard to satisfaction and the functionality of the systems.

- Personalisation: Users are given the opportunity to individually adapt their 
gamification environment via elements of user adaptation. This can have a positive effect on their identification and their engagement. The adaptation possibilities here extend from personal choice of colour, font and layout to the individual design of an avatar.

- The unexpected: The monotony of gamified processes can be a problem in long-term usage. It can be alleviated through surprise effects, unexpected rewards and hidden features in unexpected locations (so-called Easter eggs). However, the conditions for obtaining these are not known beforehand.

\subsection{Reward Systems}

The aforementioned gamification elements only acquire content and meaning through reward systems, thereby leading to the desired satisfaction of needs from the users' perspective, or to the attainment of a value that is meaningful to them. In this connection, Zichermann and Cunningham (2011) present the SAPS model that differentiates between status, access, power and "stuff" [19].

- Status denotes the position of a user or of a person in general within a community or a group, and this position can be represented, e.g. by badges or ranking lists. A group member can achieve different positions by completing particular tasks.

- Reward through access means that users can participate in particular actions or can access particular exclusive content, whereas other users have either limited access or no access at all.

- An example of rewarding users with power would be when users acquire particular rights within a community, e.g. a moderator function, whereby they can initiate and lead discussions.

- The "stuff" reward category ultimately consists of material elements from the real world, e.g. vouchers or objects.

According to Zichermann and Cunningham (2011), status rewards are the most effective in the long term, and they are valued the most by users [19]. The long-term effect of rewards decreases successively across the individual categories-status, access, power, stuff. Paharia (2013) adds new reward categories to those cited above: recognition and appreciation, as well as prosocial incentives [14]. The first two might be in the form of feedback or achieving badges and levels; the latter is more strongly focused on social interaction. In this is becomes clear that the boundaries between rewards and gamification elements are fluid.

\section{Model of Gamification User Types}

Based on Bartle (2003) and his player types in online role plays, in gamified systems different user groups can be categorised according to their preferences [48]. Player types can be classified by drawing on the expectations and desires that they associate with participation in games. The original model of player types consists of four player types: achiever, explorer, socialiser and killer [48]. The achievers are fixated on achieving the highest possible number of points; the ex- 
plorers take pleasure in investigating the game cosmos and discovering new places within this; the socialisers are mainly interested in the interaction with other players; and finally, the killers mainly want to compete with other players with the aim of eliminating competitors and emerging victorious themselves. Authors who engage with gamification, such as Kapp (2012) [9] or Zichermann and Cunningham (2011) [19], often refer to these player typesor adapt the original types such as Marczewski (2014) [23]. They all assume that it is possible to make analogies between the preferences of the aforementioned player types and the preferences of the users in gamified contexts. Addressing the question of why humans play games Lazzaro (2004) focuses on different aspects of the fun factor that is important in playing games [49]. In her " 4 Keys 2 Fun" model she differentiates four kinds of fun: hard fun, easy fun, serious fun and people fun. Hard fun (challenge) results from meeting a particularly challenging target. Easy fun (novelty) results from role playing, creative activities and satisfying curiosity. Serious fun (meaning) results from the pleasure in changing the player and his world. People fun (friendship) is based on social interaction and derives from competition as well as from working together with other players.

Based on Marczewski (2014) [23], a typology of gamification users can be created by linking Lazzaro's (2014) [49] different types of fun with the adapted player types (Bartle, 2003) [48] and the intrinsic motivating factors described above (relatedness, autonomy, mastery, purpose). In this way we get to a meaningful model that explains the motivation and engagement of different gamification types. At the same time, the individual user types can be assigned particular gamification elements that have a positive effect on the respective engagement because they address the "right" individual aspects of motivation and the respective dimensions of fun. The following Table 3 summarises the typology.

Table 3. Overview of selected key elements of gamification.

\begin{tabular}{|c|c|c|c|c|}
\hline $\begin{array}{l}\text { Gamification } \\
\text { User Types }\end{array}$ & Socialiser & Achiever & Free Spirit & Philantropist \\
\hline $\begin{array}{c}\text { Intrinsic } \\
\text { Motivation }\end{array}$ & Relatedness & Mastery & Autonomy & Purpose \\
\hline Keys to Fun & People Fun & Hard Fun & Easy Fun & Serious Fun \\
\hline Prime Mover & $\begin{array}{l}\text { - Communicate } \\
\text { - Cooperate } \\
\text { - Compete }\end{array}$ & $\begin{array}{l}\text { Goals } \\
\text { Obstacles } \\
\text { Strategy }\end{array}$ & $\begin{array}{l}\text { Exploration } \\
\text { Fantasy } \\
\text { Creativity }\end{array}$ & $\begin{array}{l}\text { Repetition } \\
\text { Rhythm } \\
\text { Collection }\end{array}$ \\
\hline $\begin{array}{c}\text { Suitable } \\
\text { Gamification } \\
\text { Elements }\end{array}$ & $\begin{array}{l}\text { - Social Connections } \\
\text { - Social Status } \\
\text { - Social Discovery } \\
\text { - Collaboration \& } \\
\text { Teams } \\
\text { - Competition }\end{array}$ & $\begin{array}{l}\text { - Levels \& } \\
\text { Progression } \\
\text { - Quests \& } \\
\text { Challenges } \\
\text { - Achievements } \\
\text { \& Rewards } \\
\text { - Leaderboards } \\
\text { - Competitions }\end{array}$ & $\begin{array}{l}\text { - Customisation } \\
\text { - Unlockable } \\
\text { Content } \\
\text { - Branching } \\
\text { Choices } \\
\text { - Creativity Tool } \\
\text { - EasterEggs }\end{array}$ & $\begin{array}{l}\text { - Gifting \& Giving } \\
\text { - Social Status } \\
\text { - Access } \\
\text { - Collectable \& } \\
\text { Tradeable } \\
\text { Rewards } \\
\text { - Collaboration \& } \\
\text { Teams }\end{array}$ \\
\hline
\end{tabular}


- Socialisers strive, even in gamified contexts, as far as possible for contact and exchange with other users. The interaction with other people makes them feel they are having fun and gives them the necessary motivation to participate. In addition, the desire for social integration has a motivating effect, and this can be used in the context of gamified systems by introducing teams and team tasks.

- Achievers are likewise based on Bartle's typology (2003) [48]. Achievers tend to strive intensely to achieve objectives and complete tasks. From the point of view of the achievers, their fun comes from recognising they have made progress in their own ability and from applying their own strategies in the completion of tasks. In this, the mastery of tasks that are challenging as possible has an intrinsically motivating effect, so that particular importance is attached to competitive elements and variable degrees of difficulty.

- The free spirit type borrows from the original explorer type. He differentiates himself, though, by wanting to exert influence on the system design. This expresses his desire to acquire space to develop his own creativity within the gamified environment. Users who are the free spirit type have a propensity for imagination and discovery. They appreciate, for example, being surprised via hidden functions, creative tools and so-called "Easter eggs". They feel entertained by curiosity and easy fun and are driven by intrinsic motivation and autonomy.

- In the gamification typology the original killers are replaced by their exact opposite: the philanthropists. This represents the biggest difference between the online gamer typology and the gamification user typology. Whereas killers want to eliminate other players in the game, philanthropists strive, as far as possible, for positive patterns of behaviour. They want to give back some of their knowledge and skills to other users, thereby making an important contribution to the community. The intrinsic motivation that actions can have a higher meaning plays an important role, as does the fun dimension of serious fun, which allows the user to feel better.

\section{Conclusions}

\subsection{Discussion}

The model of gamification user types presented here shows that it makes sense for businesses and organisations to adapt the use of gamification elements to the needs and peculiarities of individual types. Different types have different game-related preferences and therefore react with varying intensity to individual gamification elements. Socialisers prefer contact with other users, the integration of gamification and social networks, and collectively experienced actions, such as creating joint contributions. Achievers, in turn, prefer actions that involve accumulating points, ranking lists and competitions. Philanthropists prefer the possibility of transferring points to other users or social causes (donations) and the possibility of helping other users by, e.g., giving tips on internet forums. Free 
spirits in principle prefer opportunities to individually adapt the context; they prefer filter possibilities, the availability of exclusive functions, and hidden features (Easter eggs).

\subsection{Implications}

The model represents, by nature, a classification that simplifies and reduces complexity. In reality, individual users may possess characteristics from all four types. Neither can the gamification elements that address particular user types be clearly differentiated. Nonetheless, it seems wholly sensible, from a research point of view, to subject the types of gamification user to a factor analysis. Even though the individual types are not without overlap in reality, they could still be used to develop a clearer picture of the underlying tendencies with respect to certain gamification types and their preferences for different elements.

This differentiation also makes clear that for most of the potential uses, a superficial "pointification" with material rewards but unrelated to the context and to the theme of interaction cannot be the right way forward. What is required are concepts within which the gaming incentive is not only to accumulate points and obtain rewards. Instead, concepts are required which stimulate the user to set himself voluntary and simultaneously exciting challenges in an interactive and creative environment. There is a need to identify the core challenge in the respective context and support this with gaming elements.

As regards the typology, it must be kept in mind that this is constantly developing further. Thus, Marczewski (2014) has already expanded the model to include the disrupter and the player type [23]. Disrupters are motivated mainly by changing and disrupting the system and the existing rules; players react positively to game elements in particular and are predominantly fixated on rewards. Deterding (2019) furthermore states that gamification may induce stakeholders to become strategic actors gaming their organizations as best they can [2]. This further development of the model shows that gamification is currently undergoing continual development and is influenced both by technological possibilities and the changing desires and experiences of users.

\subsection{Future Directions and Limitations}

This study is a conceptual work into the motivations of players and the opportunity to use games for non-gaming contexts. Future research could use empirical and/or experimental methods to investigate peoples' experiences with gamification, for example, how gamification can contribute to management and marketing decisions and to overall business strategy. Future research also could focus on building a bridge between game studies and management literature. Since we currently face changing work environments-digital, distributed, open, creative-gamification promises to be able to provide appropriate incentives [50]. A limitation of this paper is the fact that one single literature review can impossibly cover all relevant publications in this field. Furthermore, this paper does not in- 
vestigate gamification elements or reward systems by empirical field research or by using experimental settings. It is solely based on present studies trying to combine the existing results. The study also does not focus on the impact of gamification such as an enhanced loyalty, greater customer engagement, or higher employee motivation. Since there is limited empirical evidence on these effects, further empirical surveys seem to be appropriate [6]. Future research can add to the theoretical foundations identified by this paper. However, the study offers a significant contribution to understanding how gaming can contribute to non-gaming challenges. The presented results can be used in future research to develop scientifically gamified applications in management and other non-game contexts.

\section{Conflicts of Interest}

The author declares no conflicts of interest regarding the publication of this paper.

\section{References}

[1] Schiller, F. (2016) On the Aesthetic Education of Man. Penguin Classics, London.

[2] Deterding, S. (2019) Gamification in Management: Between Choice Architecture and Humanistic Design. Journal of Management Inquiry, 28, 131-136. https://doi.org/10.1177/1056492618790912

[3] Deterding, S. (2012) Gamification: Designing for Motivation. Interactions, 19, 14-17. https://doi.org/10.1145/2212877.2212883

[4] Kim, A.J. (2008) Putting the Fun in Functional: Applying Gamemechanics to Functional Software. https://500hats.typepad.com/500blogs/2008/03/putting-the-fun.html

[5] Terlutter, R. and Capella, M.L. (2013) The Gamification of Advertising: Analysis and Research Directions of in-Game Advertising, Advergames and Advertising in Social Network Games. Journal of Advertising, 42, 95-112. https://doi.org/10.1080/00913367.2013.774610

[6] Hamari, J., Koivisto, J. and Sarsa, H. (2014) Does Gamificationwork? - A Literature Review of Empirical Studies on Gamification. 201447 th Hawaii International Conference on System Sciences, Hawaii, HI, 6-9 January 2014, 3025-3034. https://doi.org/10.1109/HICSS.2014.377

[7] Hamari, J., Huotari, K. and Tolvanen, J. (2015) Gamification from the Economics Perspective. In: Walz, S.P. and Deterding, S., Eds., The Gameful World: Approaches, Issues, Applications, MIT Press, Cambridge, 139-161.

[8] Huotari, K. and Hamari, J. (2017) A Definition for Gamification: Anchoring Gamification in the Service Marketing Literature. Electron Markets, 27, 21-31. https://doi.org/10.1007/s12525-015-0212-Z

[9] Kapp, K. (2012) The Gamification of Learning and Instruction. Game-Based Methods and Strategies for Training and Education. Pfeiffer, San Francisco, CA.

[10] Lindley, C.A. (2002) The Gameplay Gestalt, Narrative and Interactive Storytelling. In: Proceedings of Computer Games and Digital Cultures Conference, Tampere University Press, Finland.

[11] Piaget, J. (1951) Play, Dreams and Imitation in Childhood. Routledge \& Kegan Paul, 
London.

[12] Ang, C.S. (2006) Rules, Gameplay and Narratives in Video Games. Simulation \& Gaming, 37, 306-325. https://doi.org/10.1177/1046878105285604

[13] Wood, L.C. and Reiners, T. (2012) Gamification in Logistics and Supply Chain Education: Extending Active Learning. IADIS International Conference on Internet Technologies \& Society, Perth, Australia, 28-30 November 2012.

[14] Paharia, R. (2013) Loyalty 3.0: How to revoluzionize Customer and Employee Engagement with Big Data and Gamification. McGraw-Hill Book, New York.

[15] Müller, B.C., Reise, C. and Seliger, G. (2015) Gamification in Factory Management Education-A Case Study with Lego Mindstorms. Procedia CIRP, 26, 121-126. https://doi.org/10.1016/j.procir.2014.07.056

[16] Jolley, B., Mizerski, R. and Olaru, D. (2006) How Habit and Satisfaction Affects Player Retention for Online Gambling. Journal of Business Research, 59, 770-777. https://doi.org/10.1016/j.jbusres.2006.01.017

[17] Gentes, A., Guyot-Mbodji, A. and Demeure, I. (2010) Gaming on the Move: Urban Experience as a New Paradigm for Mobile Pervasive Game Design. Multimedia Systems, 16, 43-55. https://doi.org/10.1007/s00530-009-0172-2

[18] Deterding, S., Dicon, D., Khaled, R. and Year, L. (2011) From Game Design Elements to Gamefulness: Defining “Gamification”. 15th International Academic MindTrek Conference: Envisioning Future Media Environments, Tampere, Finland, 28-30 September 2011, 9-15. https://doi.org/10.1145/2181037.2181040

[19] Zichermann, G. and Cunningham, C. (2011) Gamification by Design. Implementing Game Mechanics in Web and Mobile Apps. O’Reilly Media, Sebastopol, CA.

[20] Xu, F., Tian, F., Buhalis, D., Weber, J. and Zhang H. (2015) Tourists as Mobile Gamers: Gamification for Tourism Marketing. Journal of Travel \& Tourism Marketing, 33, 1124-1142.

[21] O'Leary, D.E. (2008) Gartner's Hype Cycle and Information System Research Issues. International Journal of Accounting Information Systems, 9, 240-252. https://doi.org/10.1016/j.accinf.2008.09.001

[22] Kirst, N. (2013) Play the Game. Ideen und Know-how für Design, Werbung, Medien, 24-36.

[23] Marczewski, A. (2014) Do We Need Gamification? http://www.gamified.co.uk/2014/11/17/need-gamification

[24] Ryan, R.M., Rigby, C.S. and Przybylski, A. (2006) The Motivational Pull of Video Games: A Self-Determination Theory Approach. Motivation and Emotion, 30, 344-360. https://doi.org/10.1007/s11031-006-9051-8

[25] Boyle, E.A., Connolly, T.M., Hainey, T. and Boyle, J.M. (2012) Engagement in Digital Entertainment Games: A Systematic Review. Computers in Human Behavior, 28, 771-780. https://doi.org/10.1016/j.chb.2011.11.020

[26] Deci, E.L. and Ryan, R.M. (1985) Intrinsic Motivation and Self-Determination in Human Behavior. Plenum Publishing, New York. https://doi.org/10.1007/978-1-4899-2271-7

[27] Lucas, K. and Sherry, J. (2004) Sex Differences in Video Game Play: A Communication-Based Explanation. Communication Research, 31, 499-523. https://doi.org/10.1177/0093650204267930

[28] Yee, N. (2006) Motivations for Play in Online Games. Cyber Psychology \& Behavior, 9, 772-775. https://doi.org/10.1089/cpb.2006.9.772 
[29] Li, K.A. and Counts, S. (2007) Exploring Social Interaction and Attributes of Casual Multiplayer Mobile Gaming. In: Proceedings of the 4th International Conference on Mobile Technology, Applications and Systems and the 1 st International Symposium on Computer Human Interaction in Mobile Technology, ACM, Singapore, 696-703. https://doi.org/10.1145/1378063.1378181

[30] Tychsen, A., Hitchens, M. and Brolund, T. (2008) Motivations for Play in Computer Role-Playing Games. In: Proceedings of the 2008 Conference on Future Play: Research, Play, Share, ACM, Toronto, 57-64. https://doi.org/10.1145/1496984.1496995

[31] Frostling-Henningsson, M. (2009) First-Person Shooter Games as a Way of Connecting to People: 'Brothers in Blood'. CyberPsychology \& Behavior, 12, 557-562. https://doi.org/10.1089/cpb.2008.0345

[32] Engl, S. and Nacke, L.E. (2012) Contextual Influences on Mobile Player Experience-A Game User Experience Model. Entertainment Computing, 4, 83-91. https://doi.org/10.1016/j.entcom.2012.06.001

[33] Lin, Y.-L. and Lin, H.-W. (2011) A Study on the Goal Value for Massively Multiplayer Online Role-Playing Games Players. Computers in Human Behavior, 27, 2153-2160. https://doi.org/10.1016/j.chb.2011.06.009

[34] Lin, T.-M., Chen, S.-C. and Kuo, P.-J. (2011) Motivations for Game-Playing on Mobile Devices: Using Smartphone as an Example. In: Proceedings of the 6 th International Conference on E-Learning and Games, Edutainment Technologies, Springer Verlag, Taipei, Taiwan. https://doi.org/10.1007/978-3-642-23456-9_18

[35] Chou, C. and Tsai, M.-J. (2007) Gender Differences in Taiwan High School Students' Computer Game Playing. Computers in Human Behavior, 23, 812-824.

https://doi.org/10.1016/j.chb.2004.11.011

[36] Mintel (2009) Gaming in the Interactive World.

[37] Paras, B. and Bizzochi, J. (2005) Game, Motivation and Effective Learning: An Integrated Model for Educational Game Design. Proceedings of DiGRA 2005 Conference: Changing Views- Worlds in Play, Vancouver, Canada, 16-20 June 2005.

[38] Carrigy, T., Naliuka, K., Paterson, N. and Haahr, M. (2010) Design and Evaluation of Player Experience of a Location-Based Mobile Game. In: Proceedings of the 6 th Nordic Conference on Human-Computer Interaction: Extending Boundaries, ACM, Reykjavik, 92-101. https://doi.org/10.1145/1868914.1868929

[39] Zhou, T. (2012) Understanding the Effect of Flow on User Adoption of Mobile Games. Personal and Ubiquitous Computing, 17, 741-748. https://doi.org/10.1007/s00779-012-0613-3

[40] Huang, Y., Backman, S.J., Backman, K.F. and Moore, D. (2013) Exploring User Acceptance of 3D Virtual Worlds in Travel and Tourism Marketing. Tourism Management, 36, 490-501. https://doi.org/10.1016/j.tourman.2012.09.009

[41] Ke, W., Tan, C.-H., Sia, C.-L. and Wei, K.-K. (2012) Inducing Intrinsic Motivation to Explore the Enterprise System: The Supremacy of Organizational Levers. Journal of Management Information Systems, 29, 257-290. https://doi.org/10.2753/MIS0742-1222290308

[42] Asijavičiūtè, V. and Ušinskienè, O. (2014) Student Motivation as Decisive Factor in Prcess of ESP Learning. 156-168.

[43] Ryan, R.M. and Deci, E.L. (2000) Self-Determination Theory and the Facilitation of Intrinsic Motivation, Social Development and Well-Being. American Psychologist, 55, 68-78. https://doi.org/10.1037/0003-066X.55.1.68

[44] Csikszentmihalyi, M. (1990) Flow: The Psychology of Optimal Experience. Harper 
Perennial, New York.

[45] Csikszentmihalyi, M. (1997) Finding Flow: The Psychology of Engagement with Everyday Life. BasicBooks.

[46] Fogg, B.J. (2003) Persuasive Technology: Using Computers to Change What We Think and Do. Morgan Kaufmann, Amsterdam. https://doi.org/10.1145/764008.763957

[47] Peter, J.P. and Nord, W.R. (1982) A Clarification and Extension of Operant Conditioning Principles in Marketing. Journal of Marketing, 46, 102-107.

https://doi.org/10.1177/002224298204600315

[48] Bartle, R.R. (2003) Designing Virtual Worlds. New Riders Publishing, Indianapolis, IN.

[49] Lazzaro, N. (2004) Why We Play Games: Four Keys to More Emotion without Story. XEODesign, Inc., Oakland, CA.

[50] Moschheuser, B. and Hamari, J. (2019) The Gamification of Work: Lessons from Crowdsourcing. Journal of Management Inquiry, 28, 145-148.

https://doi.org/10.1177/1056492618790921 